\title{
Imaging Diagnostic and Therapeutic Targets: Steroid Receptors in Breast Cancer
}

\author{
Amy M. Fowler ${ }^{1}$, Amy S. Clark ${ }^{2}$, John A. Katzenellenbogen ${ }^{3}$, Hannah M. Linden ${ }^{4}$, and Farrokh Dehdashti ${ }^{5}$ \\ ${ }^{1}$ Department of Radiology, University of Wisconsin School of Medicine and Public Health, Madison, Wisconsin; ${ }^{2}$ Division of \\ Hematology and Oncology, Department of Medicine, Perelman School of Medicine, University of Pennsylvania, Philadelphia, \\ Pennsylvania; ${ }^{3}$ Department of Chemistry, University of Illinois at Urbana-Champaign, Urbana, Illinois; ${ }^{4}$ Division of Medical \\ Oncology, Department of Medicine, University of Washington, Seattle, Washington; and ${ }^{5}$ Division of Nuclear Medicine, Mallinckrodt \\ Institute of Radiology, Washington University, St. Louis, Missouri
}

\begin{abstract}
Estrogen receptor alpha (ERa) and progesterone receptor $(\mathrm{PR})$ are important steroid hormone receptor biomarkers used to determine prognosis and to predict benefit from endocrine therapies for breast cancer patients. Receptor expression is routinely measured in biopsy specimens using immunohistochemistry, although such testing can be challenging, particularly in the setting of metastatic disease. ERa and PR can be quantitatively assayed noninvasively with PET. This approach provides the opportunity to assess receptor expression and function in real time, within the entire tumor, and across distant sites of metastatic disease. This article reviews the current evidence of ERa and PR PET imaging as predictive and early-response biomarkers for endocrine therapy.
\end{abstract}

Key Words: breast cancer; estrogen receptor a; progesterone receptor; PET; imaging biomarker

J Nucl Med 2016; 57:75S-80S

DOI: 10.2967/jnumed.115.157933

$\mathbf{M}$ ore than 230,000 women in the United States are predicted to be diagnosed with breast cancer in 2015 , making it the most common malignancy among women (1). Most of these patients will be diagnosed with curable breast cancer, although 5\%-9\% will have metastatic disease at presentation (1). When breast cancer has spread to distant organs, it is mainly incurable and the goal of therapy is palliative. Treatment of metastatic breast cancer is indefinite; therefore, therapies that maximize quality and quantity of life are preferred.

The systemic therapy decision for a specific patient is based on the estrogen receptor alpha $(\mathrm{ER} \alpha)$, progesterone receptor (PR), and human epidermal growth factor receptor 2 (HER2) status of the patient's breast cancer (2). At present, receptor testing from tissue obtained from a metastatic biopsy is the standard method of ascertaining the receptor status. If tissue from a metastatic site is

Received Sep. 9, 2015; revision accepted Nov. 2, 2015.

For correspondence or reprints contact either of the following:

Hannah M. Linden, Division of Medical Oncology, Department of Medicine,

University of Washington, 825 Eastlake Ave. W., Seattle, WA 98109-1023.

E-mail: hmlinden@uw.edu

Amy M. Fowler, Department of Radiology, University of Wisconsin School of Medicine and Public Health, 600 Highland Ave., Madison, WI 53792-3252.

E-mail: afowler@uwhealth.org

COPYRIGHT (c) 2016 by the Society of Nuclear Medicine and Molecular Imaging, Inc. not available, receptor status is inferred from the primary breast tumor. For those with tumors expressing ER $\alpha$ or PR ( $>75 \%$ of all breast cancers), endocrine therapy is the preferred treatment for the first several lines of therapy. However, only $50 \%-75 \%$ of patients with $\mathrm{ER} \alpha$-positive breast cancer will respond to first-line endocrine therapy, and the response rate decreases with additional lines of therapy, with only $25 \%$ responding beyond the first line (3).

A variety of challenges exist in determining the hormone receptor status of a metastatic tumor. First, the location of the metastatic disease may not be amenable to biopsy (e.g., brain or bone), and the treating clinician will be forced to assume that the receptor status in the metastatic disease is the same as in the primary breast tumor. However, this assumption is problematic because the receptor status can differ $25 \%-40 \%$ of the time between primary breast tumors and metastatic lesions (3-5). Second, even when a bone biopsy can be performed, issues with sample processing of bone (specifically decalcification) can generate false-negative ER $\alpha$ or PR results (6). With a false-negative result, the clinician could be led away from using less toxic endocrine therapy to treat the patient. Finally, there is the issue of both intratumor and intertumor heterogeneity (7). Tumor heterogeneity is of particular relevance, because patients generally have more than one site of metastatic disease. Furthermore, not all cancer cells in a tumor will be the same. A biopsy samples only a small portion of one lesion; it is not feasible to sample each individual metastatic lesion. Thus, practitioners must assume that the one biopsy represents all of the cancer. These issues underscore the need to develop standard methods of measuring tumor heterogeneity. One method under development that can better assess tumor heterogeneity is imaging using receptor-targeted radiopharmaceuticals.

Noninvasive imaging is a useful approach for visual assessment and quantitative measurement of steroid hormone receptors both in primary breast cancer and across metastatic sites of disease. The techniques used for steroid receptor imaging have focused predominately on ${ }^{18} \mathrm{~F}$-based radiopharmaceuticals and PET alone or, more recently, in combination with CT (PET/CT) for improved anatomic colocalization. PET imaging has an advantage over other nuclear medicine techniques, such as planar imaging or SPECT, because of its excellent sensitivity to quantify radioligand binding down to picomolar concentrations (8).

Although steroid receptor PET imaging agents have not yet been approved by the U.S. Food and Drug Administration, several factors make them attractive candidates for successful translation, implementation, and acceptance into clinical use for breast cancer patients. Patient preparation for steroid receptor imaging is simpler than for 
conventional PET/CT imaging with ${ }^{18}$ F-FDG because fasting and measurement of blood glucose levels before scanning are not necessary. As with ${ }^{18}$ F-FDG PET/CT, patients are injected intravenously with the steroid receptor imaging agent and imaged approximately $1 \mathrm{~h}$ later using static emission data acquisition. The SUV of the steroid receptor imaging agent in a lesion of interest, calculated as radioactivity in the volume of interest $(\mathrm{kBq} / \mathrm{mL})$ divided by the injected dose per kilogram of body weight $(\mathrm{MBq} / \mathrm{kg})$, has been validated through correlation with in vitro receptor expression assays such as ${ }^{3} \mathrm{H}$-radioligand binding assays and immunohistochemistry (9-11). Although more sophisticated uptake measures using dynamic image acquisition and pharmacokinetic modeling have been reported, they have not been proven superior to simpler SUV measurements (10). Ease of patient preparation, image acquisition, and analysis are important factors to keep in mind when evaluating new molecular imaging agents for potential use in clinical practice.

\section{ESTROGEN RECEPTOR IMAGING}

$16 \alpha-{ }^{18} \mathrm{~F}$-fluoro-17 $\beta$-estradiol ( $\left.{ }^{18} \mathrm{~F}-\mathrm{FES}\right)$ is the most studied radiopharmaceutical to quantify $\mathrm{ER} \alpha$ and has been reported for nearly 1,000 patients participating in clinical trials as of 2013 (12). This radioligand was developed in the 1980s (13), with the first-in-human study published in 1988 by Mintun et al. (9). ${ }^{18} \mathrm{~F}-$ FES displays a favorable tissue biodistribution profile with comparable binding affinity to $\mathrm{ER} \alpha$, as does $17 \beta$-estradiol $(14) .{ }^{18} \mathrm{~F}$ FES uptake (as measured by SUV with imaging) strongly correlates with ER $\alpha$ expression - as measured by radioligand binding in fresh tissue and by immunohistochemistry in fixed tissue $(9,10)$ - as shown in Figure 1. Sensitivity and specificity data of ${ }^{18}$ F-FES imaging for the detection of ER $\alpha$-positive breast cancer are available in 4 published studies involving 114 patients $(9,10,15,16)$. The overall sensitivity and specificity were $84 \%$ (95\% confidence interval,
$73 \%-91 \%$ ) and $98 \%$ (95\% confidence interval, 90\%-100\%), respectively (12). Thus, ${ }^{18} \mathrm{~F}$-FES-PET is a good surrogate measurement of $\mathrm{ER} \alpha$ expression.

The Cancer Imaging Program of the National Cancer Institute sponsors an investigational new drug exemption from the Food and Drug Administration (IND 79,005) for ${ }^{18}$ F-FES and freely provides reference materials to the research community to assist investigators with further ${ }^{18} \mathrm{~F}$-FES clinical trials (17). They anticipate that data gained from wider use of ${ }^{18} \mathrm{~F}$-FES may eventually support a Food and Drug Administration new drug application.

\section{${ }^{18}$ F-FES as a Predictive Biomarker}

The baseline value of the ${ }^{18}$ F-FES SUV has been studied as a predictive biomarker to endocrine therapy in several small studies in patients receiving various endocrine therapies for metastatic ER $\alpha$ positive breast cancer. In all these studies, response was defined by standard clinical criteria based on symptoms and imaging. In early studies from Washington University, Dehdashti et al. (18) studied 11 patients with ${ }^{18} \mathrm{~F}$-FES PET before initiation of tamoxifen therapy. Response was assessed by the treating clinician at 2-mo intervals. The baseline ${ }^{18} \mathrm{~F}$-FES SUV was 2.2 or higher for responders and 1.7 or higher for nonresponders (18). Later, in studying 40 patients with advanced breast cancer before and after tamoxifen therapy, these investigators reported that responders had higher baseline tumor uptake of ${ }^{18} \mathrm{~F}-\mathrm{FES}$ (SUV, $4.3 \pm 62.4$ ) than did nonresponders (SUV, $1.8 \pm 61.3 ; P=0.0007$ ) (19). When the SUV cutoff of 2.0 was used, positive predictive value (PPV) was calculated to be $79 \%$ and negative predictive value (NPV) $88 \%$, slightly better than in the previous study. Subsequently, the same investigators examined 51 patients receiving an aromatase inhibitor or fulvestrant (20). Baseline SUV of ${ }^{18} \mathrm{~F}$-FES was again noted to be higher in responders $(3.5 \pm$ $2.5)$ than in nonresponders $(2.1 \pm 1.8)$. Logistic regression analysis demonstrated a $40 \%$ increase in the odds of response for every unit increase in baseline ${ }^{18}$ F-FES SUV. A prospectively defined cutoff SUV of 2 for ${ }^{18} \mathrm{~F}$-FES was considered positive for ER expression, above which patients were more likely to respond to aromatase inhibitor or fulvestrant therapy. Based on the SUV cutoff of 2.0, PPV and NPV of ${ }^{18}$ F-FES PET were calculated to be $50 \%$ and $81 \%$, respectively (20). Finally, baseline ${ }^{18} \mathrm{~F}-\mathrm{FES}$ SUV and response at 6 mo were examined in a fourth study at the University of Washington, this one of 47 patients, many of whom had previously received tamoxifen therapy and were scheduled to begin a different salvage endocrine therapy (21). In receiver-operatingcharacteristic analysis, ${ }^{18} \mathrm{~F}$-FES SUV greater than 1.5 was associated with response to therapy. None of the 15 patients with an SUV less than the threshold of 1.5 responded to hormonal therapy. On the other hand, 11 of 32 with an SUV greater than 1.5 (higher than the threshold) responded. This was statistically significant $(P<0.01)$. Of note, patients with HER2-positive disease who received trastuzumab were permitted in this study; 
however, none of these patients were classified as responders (21).

Van Kruchten et al. (12) combined the results of these 4 studies and determined that lack of response to endocrine therapy was predicted by an ${ }^{18} \mathrm{~F}$-FES SUV of less than 1.5 in this heterogeneous group of patients. Using the 1.5 threshold, 96 of 114 patients would have been selected to receive endocrine therapy, and 62 of these would have had a clinical benefit (PPV, 65\%). Alternatively, of the 42 patients with an ${ }^{18} \mathrm{~F}$-FES SUV of less than 1.5, 37 derived no clinical benefit from endocrine therapy (NPV, 88\%). Van Kruchten et al. also examined a cutoff of 2.0 and found that $31 \%$ of patients who responded to endocrine therapy would have been considered ${ }^{18}$ F-FES-negative using this cutoff and thus potentially would not have received the endocrine therapy to which they responded. Finally, a fifth study of 15 patients showed that 2 of 2 patients with low baseline ${ }^{18} \mathrm{~F}$-FES uptake had progressive disease at $6 \mathrm{mo}$ (22). These data would imply that a cutoff of 1.5 is most appropriate if using ${ }^{18} \mathrm{~F}$ FES PET as a tool to predict response to endocrine therapy; the data further would suggest that patients with disease having ${ }^{18} \mathrm{~F}-\mathrm{FES}$ SUVs less than 1.5 should potentially receive cytotoxic therapy rather than endocrine therapy. However, before ${ }^{18} \mathrm{~F}$-FES is used in clinical practice, larger studies are needed to further refine and validate the threshold cutoff.

A potential advantage of ${ }^{18} \mathrm{~F}-\mathrm{FES}$ imaging is visualization of multiple lesions and hence appreciation of the true heterogeneity of uptake across the entire burden of tumor (23). Although ${ }^{18} \mathrm{~F}$ FES can be measured at multiple tumor sites, uptake in the liver is confounded by clearance of the tracer; therefore, ${ }^{18} \mathrm{~F}-\mathrm{FES}$ cannot measure tumor uptake at this common site of breast cancer metastasis. Because the standard of care is one biopsy sample, little is known about the significance of heterogeneity in predicting response. Further studies are needed to understand the predictive value of knowledge of ER binding at multiple sites.

\section{${ }^{18}$ F-FES to Monitor Efficacy of Receptor Blockade and Response to Antiestrogen Therapy}

Serial imaging is a standard method of evaluating response to treatment, and ${ }^{18} \mathrm{~F}$-FES PET has been evaluated in such a fashion in a few small trials. In the previously discussed trial of 40 patients receiving first-line tamoxifen for metastatic ER $\alpha$-positive metastatic breast cancer, ${ }^{18} \mathrm{~F}$-FES PET was obtained at baseline and 7-10 $\mathrm{d}$ after initiation of therapy. ${ }^{18} \mathrm{~F}-\mathrm{FES}$ SUV in lesions of responders decreased at the second time point compared with baseline. The decrease in ${ }^{18} \mathrm{~F}-\mathrm{FES}$ SUV after 7-10 d of tamoxifen was $54.8 \% \pm$ $14.2 \%$ in responders and $19.4 \% \pm 17.3 \%$ in nonresponders $(P=$ $0.0003)$. The mean change in ${ }^{18} \mathrm{~F}-\mathrm{FES}$ SUV was also higher among responders $(-2.5 \pm 1.8)$ than among nonresponders $(-0.5 \pm 0.6)$ (19). These results suggest that an early evaluation after introduction of tamoxifen can help determine who will respond by monitoring the efficacy of tamoxifen to block ${ }^{18} \mathrm{~F}$-FES binding to ER $\alpha$.

A similar approach has also been studied for determining the optimal dose of ER $\alpha$ antagonists needed for complete suppression of ${ }^{18} \mathrm{~F}$-FES uptake in serial imaging. Linden et al. (24) reported a retrospective study of patients with metastatic breast cancer and a prior ER $\alpha$-positive primary diagnosis undergoing ${ }^{18} \mathrm{~F}$-FES PET/CT before and after the initiation of salvage endocrine therapy. Complete blockade of tumor ${ }^{18} \mathrm{~F}$-FES uptake was observed for all patients treated with tamoxifen (5/5) but for only 36\% (4/11) of patients treated with fulvestrant (24). Those authors concluded that the dosing of fulvestrant was insufficient for complete ER $\alpha$ inhibition, but they did not have data on subsequent patient clinical responses to correlate. A subsequent prospective study of 16 patients with ER $\alpha$ positive metastatic breast cancer treated with the current standard dose of $500 \mathrm{mg}$ of intramuscular fulvestrant was performed to measure $\mathrm{ER} \alpha$ availability for ${ }^{18} \mathrm{~F}-\mathrm{FES}$ binding before and during therapy (25). Residual ${ }^{18}$ F-FES uptake was observed in $38 \%(6 / 16)$ of patients treated with fulvestrant, which was associated with early clinical disease progression (25). Use of ${ }^{18} \mathrm{~F}$-FES PET/CT for determining optimal ER $\alpha$ inhibition could also be applied to new drug development and evaluation, as reported in a recent scientific meeting abstract for an investigational oral selective estrogen-receptor degrader, ARN-810 (26).

\section{Summary}

Thus, through its investigation in clinical trials, ${ }^{18} \mathrm{~F}-\mathrm{FES}$ appears to be a predictive biomarker for identifying patients with $\mathrm{ER} \alpha$-positive metastatic breast cancer who will respond to endocrine therapy, as well as a useful tool to assess the pharmacodynamics of endocrine therapy at early times. Larger studies are necessary to better determine and validate the ${ }^{18} \mathrm{~F}-\mathrm{FES} \mathrm{SUV}$ threshold above which clinicians can report response to therapy; these studies will also aid in better determining the sensitivity and specificity of baseline ${ }^{18} \mathrm{~F}-\mathrm{FES}$ SUVs to predict response (27). Such a study is about to open through the Eastern Cooperative Oncology Group/American College of Radiology Imaging Network (ECOG/ACRIN) consortium (NCT02398773), which will enroll patients receiving first-line endocrine-based therapy for $\mathrm{ER} \alpha$ positive metastatic breast cancer.

\section{PROGESTERONE RECEPTOR IMAGING}

As with $\mathrm{ER} \alpha$, prognostic and predictive information can be gained from knowledge of PR status. Therefore, PR is routinely assayed along with $\mathrm{ER} \alpha$ as part of the standard immunohistochemical analysis of newly diagnosed breast cancers and their recurrences (28). Because ER $\alpha$ and PR expression in breast cancer are strongly associated, ER $\alpha$-negative, PR-positive tumors are uncommon and may be caused by a false-negative ER $\alpha$ immunohistochemical result (29). However, endocrine therapy remains an option for patients with ER $\alpha$-negative, PR-positive breast cancers.

$\mathrm{PR}$ is a classic estrogen-regulated gene, the expression of which depends on a functional ER $\alpha$-signaling pathway (30). Thus, PR is a pharmacodynamic or early-response biomarker: "a downstream biomarker that can be used as a surrogate measure of response to treatment-induced modulation of the upstream signaling components" (31). For example, an increase in PR protein as measured on repeat biopsy shortly after initiating tamoxifen that resulted from its partial agonist activity correlated with prolonged time to progression and improved survival (32). Supporting this notion is the observation that patients with metastatic ER $\alpha$-positive, PR-positive breast cancer are the most likely to benefit from endocrine therapy (33).

The most promising PET agent for imaging PR is $21-{ }^{18} \mathrm{~F}$-fluoro$16 \alpha, 17 \alpha-\left[(R)-\left(1^{\prime}-\alpha\right.\right.$-furylmethylidene $)$ dioxy $]$-19-norpregn-4-ene3,20 -dione ( ${ }^{18} \mathrm{~F}$-FFNP). This radioligand was developed in the 1990s and fulfills several important criteria for effective steroid receptor imaging $(34,35)$. It has a high relative binding affinity to PR and a low nonspecific binding and thus a high binding selectivity index $(34,35)$. Recently optimized and automated synthesis methods result in a final product with good yield ( $\leq 77 \%)$, high radiochemical purity, and high specific activity $(48,100-314,500$ MBq [1,300-8,500 mCi]/ $/ \mu \mathrm{mol}$ ) (36). Tissue biodistribution studies in estrogen-primed female rats demonstrated high PR-selective uptake in the uterus and ovaries (34). Importantly, ${ }^{18} \mathrm{~F}$-FFNP 
exhibits minimal defluorination, evidenced by low bone uptake, and is less prone to metabolism by dehydrogenases, which was the major factor in the unsuccessful application of an earlier PR imaging agent, $21-{ }^{18} \mathrm{~F}$-fluoro-16 $\alpha$-ethyl-19-norprogesterone ( $\left.{ }^{18} \mathrm{~F}-\mathrm{FENP}\right)$, in humans (37).

\section{${ }^{18}$ F-FFNP to Monitor Response to Endocrine Therapy}

The hypothesis that changes in PR as seen on imaging can be an early-response biomarker of treatment-induced changes in an upstream ER-signaling pathway has been tested in preclinical breast cancer models $(38,39)$. These studies show that an early decrease in tumoral ${ }^{18} \mathrm{~F}$-FFNP uptake predicts responsiveness to fulvestrant and estrogen-deprivation therapy. Decreases in ${ }^{18} \mathrm{~F}$-FFNP uptake occurred before changes in tumor growth. Furthermore, monitoring ER $\alpha$ function through imaging PR with longitudinal ${ }^{18} \mathrm{~F}$-FFNP PET was more predictive of response to estrogen-deprivation therapy than was ${ }^{18} \mathrm{~F}$-FES PET or ${ }^{18} \mathrm{~F}$-FDG PET (39). These preclinical data provide the proof of principle to support further translational studies in breast cancer patients.

The first-in-human study of ${ }^{18}$ F-FFNP was published in 2012 and provided safety and dosimetry data on 20 women with breast cancer (Fig. 2) (11). No adverse or pharmacologic effects of the injected mass dose $(1.34 \pm 1.24 \mu \mathrm{g})$ were observed. The wholebody effective dose for ${ }^{18} \mathrm{~F}$-FFNP was $0.020 \mathrm{mSv} / \mathrm{MBq}$, which is similar to that for ${ }^{18} \mathrm{~F}$-FES $(0.022 \mathrm{mSv} / \mathrm{MBq})$ and ${ }^{18} \mathrm{~F}-\mathrm{FDG}(0.024$ $\mathrm{mSv} / \mathrm{Bq})(11,40,41)$. As with ${ }^{18} \mathrm{~F}-\mathrm{FES},{ }^{18} \mathrm{~F}-\mathrm{FFNP}$ is eliminated by hepatobiliary clearance. Thus, evaluation of ${ }^{18} \mathrm{~F}$-FFNP uptake in liver lesions is a potential limitation.

In addition to investigating safety and dosimetry, correlation of ${ }^{18}$ F-FFNP uptake with in vitro PR measurement via immunohistochemistry was performed by Dehdashti et al. (11). In their patient population with 16 PR-positive and 6 PR-negative primary breast cancers, tumor-to-normal breast tissue uptake ratios of ${ }^{18} \mathrm{~F}$ FFNP were greater in PR-positive cancers $(2.6 \pm 0.9)$ than in PRnegative cancers $(1.5 \pm 0.3 ; P=0.001)(11)$. Dynamic imaging demonstrated rapid ${ }^{18} \mathrm{~F}$-FFNP uptake within the PR-positive tumor and showed no significant washout over the 60-min imaging interval (11). Thus, ${ }^{18} \mathrm{~F}-\mathrm{FFNP}$ PET can be safely used in patients to assess the PR status of breast cancer.

Investigations into the usefulness of ${ }^{18} \mathrm{~F}-\mathrm{FFNP}$ PET as an earlyresponse biomarker for endocrine therapy are in progress. The clinical trial NCT02455453 aims to measure ${ }^{18}$ F-FFNP uptake before and after administration of estradiol for $1 \mathrm{~d}$ (estradiol challenge) for postmenopausal patients with ER $\alpha$-positive breast cancer to determine whether the change in ${ }^{18} \mathrm{~F}$-FFNP uptake is predictive of response to endocrine therapy. Furthermore, preclinical studies have demonstrated that ${ }^{18} \mathrm{~F}$-FFNP uptake of hormonesensitive mouse mammary tumors increases in response to estradiol treatment (38).

\section{Summary}

Clinical studies of PR PET imaging significantly lag behind those of $\mathrm{ER} \alpha$, and considerable work is still required before ${ }^{18} \mathrm{~F}$ FFNP is ready for translation into clinical practice. Larger-scale investigations are needed into the sensitivity and specificity of ${ }^{18} \mathrm{~F}$ FFNP PET for the detection of PR, and its usefulness as an earlyresponse biomarker for endocrine therapy; these studies should then undergo subsequent validation through multiinstitutional studies. Comparison might also be considered of the performance of ${ }^{18} \mathrm{~F}$-FFNP with ${ }^{18} \mathrm{~F}$-radiolabeled and ${ }^{11} \mathrm{C}$-radiolabeled Tanaproget (ApexBio), a nonsteroidal progestin analog with in vitro and preclinical data demonstrating a high binding affinity for PR and less cross-reactivity with glucocorticoid and androgen receptors (42-44).

\section{FUTURE DIRECTIONS}

\section{Combined ERa and PR Imaging}

Information gained from imaging with both ${ }^{18} \mathrm{~F}-\mathrm{FES}$ and ${ }^{18} \mathrm{~F}-$ FFNP could result in the highest predictive power for response to endocrine therapy. A baseline ${ }^{18} \mathrm{~F}$-FES PET examination would determine whether the therapeutic target $(\mathrm{ER} \alpha)$ is present in some, most, or all of a patient's metastatic lesions, thus providing important information about tumor heterogeneity. The strength of $\mathrm{ER} \alpha$ imaging with ${ }^{18} \mathrm{~F}$-FES is its high NPV (88\%); that is, if the ${ }^{18}$ F-FES SUV is less than 1.5 , patients are very unlikely to have a clinical benefit from endocrine therapy (12). However, the PPV of ${ }^{18}$ F-FES PET is only $65 \%$ (12). Thus, the presence of ER $\alpha$ capable of binding to ${ }^{18} \mathrm{~F}-\mathrm{FES}$ does not guarantee its function. Baseline and short-follow-up ${ }^{18}$ F-FFNP PET imaging after endocrine therapy initiation or estradiol challenge may be helpful as a probe of PR expression to confirm a functional ER $\alpha$-driven pathway. However, a drawback of using ${ }^{18} \mathrm{~F}$ radioligands for this approach is the inability to image using more than one radiopharmaceutical at a time, thus requiring repeated longitudinal PET/CT studies, which raises potential concerns regarding radiation exposure. Fortuitously, simultaneous PET/MRI scanners have recently been developed for clinical use that can reduce radiation exposure by eliminating the CT component of the examination and thus be a more suitable modality for serial imaging to assess therapy response.

\section{Steroid Receptor Imaging in the Era of Personalized Cancer Medicine}

Evidence is increasing of the complementary role of targeted therapy of growth factor activation and cell-cycle control pathways with endocrine therapy for patients with recurrent or metastatic breast cancer. Indications for this approach have been recently incorporated into clinical practice guidelines $(2,45)$. These treatments include everolimus, an inhibitor of the phosphatidylinositol 3-kinase/mammalian target of rapamycin (PI3K/mTOR) pathway, in combination
FIGURE 2. Representative transverse CT (left) and fused ${ }^{18}$ F-FFNP PET/CT (right) images in patient with PR-positive breast cancer demonstrate focally increased uptake in known cancer in left breast (arrows). 
with exemestane, a steroidal aromatase enzyme inactivator; and palbociclib, a cyclin-dependent kinase 4/6 inhibitor, in combination with fulvestrant or letrozole, a nonsteroidal aromatase inhibitor. The ability of steroid receptor imaging to predict response to these types of combined endocrine and molecular pathway-targeted therapies will need to be investigated.

In this emerging era of precision medicine and big data, we will also need to consider how information gained from molecular imaging is best integrated with "-omics"-level tissue data. For breast cancer, these assays include measuring the overall gene expression pattern for molecular subtyping (46); measuring a subset of 21 genes to quantify the likelihood of distant recurrence in tamoxifen-treated patients with axillary lymph node-negative, $\mathrm{ER} \alpha$-positive primary breast cancer (47); and whole-genome sequencing of metastatic tumor samples to identify gene mutations that respond to medications (48). An approach that incorporates molecular imaging with genomics tissue data may improve the overall clinical usefulness of the individual tests. A multidisciplinary approach, such as a molecular genomics and imaging tumor board, would be the ideal setting for guiding clinical decision making, particularly for patients with progressive metastatic breast cancer.

\section{DISCLOSURE}

No potential conflict of interest relevant to this article was reported.

\section{REFERENCES}

1. Siegel RL, Miller KD, Jemal A. Cancer statistics, 2015. CA Cancer J Clin. 2015;65:5-29.

2. National Comprehensive Cancer Network Guidelines Version 1.2015 Invasive Breast Cancer. http://www.nccn.org. Accessed December 19, 2015.

3. Osborne CK, Schiff R. Mechanisms of endocrine resistance in breast cancer. Annu Rev Med. 2011;62:233-247.

4. Niikura N, Liu J, Hayashi N, et al. Loss of human epidermal growth factor receptor 2 (HER2) expression in metastatic sites of HER2-overexpressing primary breast tumors. J Clin Oncol. 2012;30:593-599.

5. Amir E, Miller N, Geddie W, et al. Prospective study evaluating the impact of tissue confirmation of metastatic disease in patients with breast cancer. J Clin Oncol. 2012;30:587-592.

6. Gertych A, Mohan S, Maclary S, et al. Effects of tissue decalcification on the quantification of breast cancer biomarkers by digital image analysis. Diagn Pathol. 2014;9:213.

7. Gerlinger M, Rowan AJ, Horswell S, et al. Intratumor heterogeneity and branched evolution revealed by multiregion sequencing. N Engl J Med. 2012;366: 883-892.

8. James ML, Gambhir SS. A molecular imaging primer: modalities, imaging agents, and applications. Physiol Rev. 2012;92:897-965.

9. Mintun MA, Welch MJ, Siegel BA, et al. Breast cancer: PET imaging of estrogen receptors. Radiology. 1988;169:45-48.

10. Peterson LM, Mankoff DA, Lawton T, et al. Quantitative imaging of estrogen receptor expression in breast cancer with PET and ${ }^{18} \mathrm{~F}$-fluoroestradiol. $\mathrm{J} \mathrm{Nucl}$ Med. 2008;49:367-374.

11. Dehdashti F, Laforest R, Gao F, et al. Assessment of progesterone receptors in breast carcinoma by PET with $21-^{18} \mathrm{~F}$-fluoro- $16 \alpha, 17 \alpha-\left[(\mathrm{R})-\left(1^{\prime}-\right.\right.$ $\alpha$-furylmethylidene)dioxy]-19-norpregn- 4-ene-3,20-dione. J Nucl Med. 2012;53: 363-370.

12. van Kruchten M, de Vries EG, Brown M, et al. PET imaging of oestrogen receptors in patients with breast cancer. Lancet Oncol. 2013;14:e465-e475.

13. Mathias CJ, Welch MJ, Katzenellenbogen JA, et al. Characterization of the uptake of 16 alpha-( ${ }^{18} \mathrm{~F}$-fluoro)-17 beta-estradiol in DMBA-induced mammary tumors. Int J Rad Appl Instrum B. 1987;14:15-25.

14. Kiesewetter DO, Kilbourn MR, Landvatter SW, Heiman DF, Katzenellenbogen JA, Welch MJ. Preparation of four fluorine-18-labeled estrogens and their selective uptakes in target tissues of immature rats. J Nucl Med. 1984;25:1212-1221.
15. Dehdashti F, Mortimer JE, Siegel BA, et al. Positron tomographic assessment of estrogen receptors in breast cancer: comparison with FDG-PET and in vitro receptor assays. J Nucl Med. 1995;36:1766-1774.

16. Mortimer JE, Dehdashti F, Siegel BA, Katzenellenbogen JA, Fracasso P, Welch MJ. Positron emission tomography with $2-{ }^{18}$ F-fluoro-2-deoxy-D-glucose and $16 \alpha-{ }^{18}$ F-fluoro- $17 \beta$-estradiol in breast cancer: correlation with estrogen receptor status and response to systemic therapy. Clin Cancer Res. 1996;2:933939.

17. ${ }^{18}$ F-fluoroestradiol, ${ }^{18}$ F-FES: frequently asked questions. National Cancer Institute website. http://imaging.cancer.gov/images/documents/FES-FAQ-flyer.pdf. Published June 2012. Accessed December 1, 2015.

18. Dehdashti F, Flanagan FL, Mortimer JE, Katzenellenbogen JA, Welch MJ, Siegel BA. Positron emission tomographic assessment of "metabolic flare" to predict response of metastatic breast cancer to antiestrogen therapy. Eur J Nucl Med. 1999;26:51-56.

19. Mortimer JE, Dehdashti F, Siegel BA, Trinkaus K, Katzenellenbogen JA, Welch MJ. Metabolic flare: indicator of hormone responsiveness in advanced breast cancer. J Clin Oncol. 2001;19:2797-2803.

20. Dehdashti F, Mortimer JE, Trinkaus K, et al. PET-based estradiol challenge as a predictive biomarker of response to endocrine therapy in women with estrogenreceptor-positive breast cancer. Breast Cancer Res Treat. 2009;113:509-517.

21. Linden HM, Stekhova SA, Link JM, et al. Quantitative fluoroestradiol positron emission tomography imaging predicts response to endocrine treatment in breast cancer. J Clin Oncol. 2006;24:2793-2799.

22. Peterson LM, Kurland BF, Schubert EK, et al. A phase 2 study of $16 \alpha-{ }^{18} \mathrm{~F}$ fluoro-17 $\beta$-estradiol positron emission tomography (FES-PET) as a marker of hormone sensitivity in metastatic breast cancer (MBC). Mol Imaging Biol. 2014; 16:431-440.

23. Kurland BF, Peterson LM, Lee JH, et al. Between-patient and within-patient (site-to-site) variability in estrogen receptor binding, measured in vivo by ${ }^{18} \mathrm{~F}$ fluoroestradiol PET. J Nucl Med. 2011;52:1541-1549.

24. Linden HM, Kurland BF, Peterson LM, et al. Fluoroestradiol positron emission tomography reveals differences in pharmacodynamics of aromatase inhibitors, tamoxifen, and fulvestrant in patients with metastatic breast cancer. Clin Cancer Res. 2011;17:4799-4805.

25. van Kruchten M, de Vries EG, Glaudemans AW, et al. Measuring residual estrogen receptor availability during fulvestrant therapy in patients with metastatic breast cancer. Cancer Discov. 2015;5:72-81.

26. Wang Y, Ulaner G, Manning H, et al. Validation of target engagement using ${ }^{18} \mathrm{~F}$ fluoroestradiol PET in patients undergoing therapy with selective estrogen receptor degrader, ARN-810 (GDC-0810) [abstract]. J Nucl Med. 2015;56(suppl 3):177P.

27. Linden HM, Dehdashti F. Novel methods and tracers for breast cancer imaging. Semin Nucl Med. 2013;43:324-329.

28. Hammond ME, Hayes DF, Dowsett M, et al. American Society of Clinical Oncology/College of American Pathologists guideline recommendations for immunohistochemical testing of estrogen and progesterone receptors in breast cancer (unabridged version). Arch Pathol Lab Med. 2010;134:e48-e72.

29. Nadji M, Gomez-Fernandez C, Ganjei-Azar P, Morales AR. Immunohistochemistry of estrogen and progesterone receptors reconsidered: experience with 5,993 breast cancers. Am J Clin Pathol. 2005;123:21-27.

30. Horwitz KB, McGuire WL. Estrogen control of progesterone receptor in human breast cancer: correlation with nuclear processing of estrogen receptor. $J$ Biol Chem. 1978;253:2223-2228.

31. Holland JP, Cumming P, Vasdev N. PET of signal transduction pathways in cancer. J Nucl Med. 2012;53:1333-1336.

32. Howell A, Harland RN, Barnes DM, et al. Endocrine therapy for advanced carcinoma of the breast: relationship between the effect of tamoxifen upon concentrations of progesterone receptor and subsequent response to treatment. Cancer Res. 1987;47:300-304.

33. Horwitz KB, McGuire WL. Predicting response to endocrine therapy in human breast cancer: a hypothesis. Science. 1975;189:726-727.

34. Buckman BO, Bonasera TA, Kirschbaum KS, Welch MJ, Katzenellenbogen JA. Fluorine-18-labeled progestin 16 alpha, 17 alpha-dioxolanes: development of high-affinity ligands for the progesterone receptor with high in vivo target site selectivity. J Med Chem. 1995;38:328-337.

35. Vijaykumar D, Mao W, Kirschbaum KS, Katzenellenbogen JA. An efficient route for the preparation of a 21 -fluoro progestin-16 $\alpha, 17 \alpha$-dioxolane, a high-affinity ligand for PET imaging of the progesterone receptor. J Org Chem. 2002;67: 4904-4910.

36. Zhou D, Lin M, Yasui N, et al. Optimization of the preparation of fluorine-18labeled steroid receptor ligands $16 \alpha-{ }^{18} \mathrm{~F}$-fluoroestradiol (FES), ${ }^{18} \mathrm{~F}$-fluoro furanyl norprogesterone (FFNP), and $16 \beta-{ }^{18} \mathrm{~F}$-fluoro-5 $\alpha$-dihydrotestosterone (FDHT) as radiopharmaceuticals. J Labelled Comp Radiopharm. 2014;57:371-377. 
37. Dehdashti F, McGuire AH, Van Brocklin HF, et al. Assessment of 21-18 F-fluoro$16 \alpha$-ethyl-19-norprogesterone as a positron-emitting radiopharmaceutical for the detection of progestin receptors in human breast carcinomas. J Nucl Med. 1991;32: 1532-1537.

38. Fowler AM, Chan SR, Sharp TL, et al. Small-animal PET of steroid hormone receptors predicts tumor response to endocrine therapy using a preclinical model of breast cancer. J Nucl Med. 2012;53:1119-1126.

39. Chan SR, Fowler AM, Allen JA, et al. Longitudinal noninvasive imaging of progesterone receptor as a predictive biomarker of tumor responsiveness to estrogen deprivation therapy. Clin Cancer Res. 2015;21:1063-1070.

40. Mankoff DA, Peterson LM, Tewson TJ, et al. ${ }^{18} \mathrm{~F}$-fluoroestradiol radiation dosimetry in human PET studies. J Nucl Med. 2001;42:679-684.

41. Mejia AA, Nakamura T, Masatoshi I, Hatazawa J, Masaki M, Watanuki S. Estimation of absorbed doses in humans due to intravenous administration of fluorine-18-fluorodeoxyglucose in PET studies. J Nucl Med. 1991;32: 699-706.

42. Zhou HB, Lee JH, Mayne CG, Carlson KE, Katzenellenbogen JA. Imaging progesterone receptor in breast tumors: synthesis and receptor binding affinity of fluoroalkyl-substituted analogues of Tanaproget. J Med Chem. 2010;53:33493360 .
43. Lee JH, Zhou HB, Dence CS, Carlson KE, Welch MJ, Katzenellenbogen JA. Development of F-18-fluorine-substituted Tanaproget as a progesterone receptor imaging agent for positron emission tomography. Bioconjug Chem. 2010;21: 1096-1104.

44. Haywood T, Kealey S, Sanchez-Cabezas S, et al. Carbon-11 radiolabelling of organosulfur compounds: ${ }^{11} \mathrm{C}$ synthesis of the progesterone receptor agonist Tanaproget. Chemistry. 2015;21:9034-9038.

45. Nagaraj G, Ma C. Revisiting the estrogen receptor pathway and its role in endocrine therapy for postmenopausal women with estrogen receptorpositive metastatic breast cancer. Breast Cancer Res Treat. 2015;150: 231-242.

46. Perou CM, Sorlie T, Eisen MB, et al. Molecular portraits of human breast tumours. Nature. 2000;406:747-752.

47. Paik S, Shak S, Tang G, et al. A multigene assay to predict recurrence of tamoxifen-treated, node-negative breast cancer. N Engl J Med. 2004;351: 2817-2826.

48. Vasan N, Yelensky R, Wang K, et al. A targeted next-generation sequencing assay detects a high frequency of therapeutically targetable alterations in primary and metastatic breast cancers: implications for clinical practice. Oncologist. 2014;19:453-458. 